\title{
Preface: Sponge research developments
}

\author{
M. Maldonado $\cdot$ X. Turon $\cdot$ M. A. Becerro • \\ M. J. Uriz
}

Published online: 28 February 2012

(C) Springer Science+Business Media B.V. 2012

Since 1970, world-wide experts on virtually every aspect of sponge biology have met together once every 4-8 years to present and discuss the latest developments in sponge research. The diverse contributions to each meeting have been published together as monographic proceedings, each book establishing a landmark reference (often more than 500 pages) on Sponge Science, and contributing collectively ( 7 books) to the establishment of a meaningful tradition. This current book "Ancient animals, new challenges: developments in sponge research," published as a special volume of the international journal Hydrobiologia, has attempted to continue this tradition by collecting contributions presented to the VIII World Sponge Conference, held by the Centre d'Estudis Avançats de Blanes (CEAB-CSIC) in Girona, Spain in September 2010.

The Conference hosted a total of 270 attendants from 36 countries, who presented 354 contributions. The Scientific Program included the topics of Evolution and Phylogeny, Organism and Cell Biology, Population Biology, Ecology, Natural Products,

Guest editors: M. Maldonado, X. Turon, M. A. Becerro \& M. J. Uriz / Ancient animals, new challenges: developments in sponge research

M. Maldonado $(\bowtie) \cdot X$. Turon $\cdot$ M. A. Becerro ·

M. J. Uriz

Department of Marine Ecology, Center for Advanced Studies of Blanes (CEAB-CSIC), Blanes, Girona, Spain

e-mail: maldonado@ceab.csic.es
Sponges and Society, and Taxonomy. The present volume includes a subset of this research (27 articles), and hopefully will offer a window to the forefront of Sponge Science and its implications in Marine Life Science. The collection of articles reflects hot, ongoing debates in molecular research, such as the monophyletic versus paraphyletic nature of the sponge group, or the new awareness on pros and cons of standard barcodes and other markers in sponge taxonomy and phylogeny. It also features articles showing how the new sequencing technologies reveal the functional and phylogenetic complexity of the "microbial universe" associated to sponge tissues. The ecological interactions of sponges, the effects of nutrients and pollutants, the variability in reproductive patterns, and the processes generating genotypic and phenotypic variability in sponge populations are also covered in several contributions. Zoogeography, population structure and dynamics are also approached with both traditional and molecular tools. The effect of anthropogenic disturbance on the natural environment also finds its place in this volume, with papers dealing with metal accumulation and the potential role of sponges as biomonitors. Biodiversity data from unexplored tropical and deep sea areas are also presented.

Because the number of papers included in the volume is relatively low compared to the total of contributions to the Conference, it can be argued that we, the Guest Editors, missed the tradition of getting the bulk of the Conference published. Massive publication would only have been possible under the 
preceding format of monographic books, which has the potential drawback that all those relevant contributions are not indexed by conventional bibliographic databases, and are thus not readily available to interested readers. Publishing through Hydrobiologia guarantees wide diffusion and rapid accessibility. Nevertheless, we acknowledge a bias in the volume content relative to the wider richness and diversity of approaches presented to the VIII World Sponge Conference. The scope of the journal clearly focuses on molecular and experimental, hypothesis-driven studies, and this non-negotiable criterion has left out some solid descriptive work on biology, ecology, and taxonomy. We strived to find a compromise between our wish to see many of the papers presented in the Conference published and the serious limitations of space and scope inherent to an international journal such as Hydrobiologia. Honestly, we experienced a bittersweet feeling when seeing the book progressively growing with excellent contributions while we were aware that important work fell outside the scope of this journal and could not be accommodated in this volume. Our apologies if some "regular" contributors to the previous seven Sponge Conference Proceedings may have felt frustrated with the process of manuscript selection. Yet we hope the readers will enjoy the following selection of papers, which we believe represent collectively a significant contribution to our current understanding of sponges.

We would also like to give our explicit thanks to the sponsoring organizations, the people who helped in the organization of the Conference, keynote speakers and all participants, in particular those who submitted manuscripts to be considered in this volume, as well as the constructive reviewers who helped to get the best out of the manuscripts. We also thank Dr. Koen Martens, Editor-in-Chief of Hydrobiologia, who made an undeniable extra-effort to seek for excellence in all aspects of the manuscripts.

Finally, we want this volume to be a tribute to the several colleagues who passed away recently, having left behind outstanding pieces of work that have inspired several generations of students and researchers. Our homage to Dr. $\mathbf{M}^{\mathrm{a}}$. Antonia Bibiloni and Professors Michelle Sara, Max Pavans de Ceccatty Patricia Bergquist, Solange Peixinho, Peter Murphy, and Lidia Scalera-Liaci. Their friendship, either if grown through close, daily work or emerged through sporadic mailing or conference contact, will always remain in our memories. 